\title{
Impact of HIV and chronic kidney disease comorbidities on hepatitis C treatment choices, drug-drug interactions and hepatitis $\mathrm{C}$ cure
}

\author{
Salamat Ali $^{1} \oplus \cdot$ Tofeeq Ur-Rehman $^{1} \cdot$ Eleri Lougher $^{2} \cdot$ David Mutimer $^{3} \cdot$ Mashhood Ali $^{4} \cdot$ Vibhu Paudyal $^{5} \oplus$
}

Received: 8 July 2019 / Accepted: 12 February 2020 / Published online: 25 February 2020

(c) The Author(s) 2020

\begin{abstract}
Background Human immunodeficiency virus (HIV) co-infection and chronic kidney disease add challenges to hepatitis C virus treatment. Objective To conduct a comparative study of treatment choices, drug-drug interactions and clinical outcomes in hepatitis C mono-infected patients, or those with HIV or chronic kidney disease comorbidities. Setting Hepatitis C treatment centers of West Midlands England, United Kingdom. Method An observational study was conducted analyzing datasets of all hepatitis $C$ patients that were referred to a large tertiary liver unit in the West Midlands, UK between July 2015 and January 2018. Patients aged $\geq 18$ years with diagnosis of hepatitis $C$ alone or co-infected with HIV or comorbid with chronic kidney disease were eligible. Main outcome measures The treatment choices, relevant potential drug-drug interactions and sustained virologic response 12 weeks post end of treatment were assessed. Results Out of 313 patients, 154 (49.2\%) were hepatitis C mono-infected, 124 (39.6\%) hepatitis C/HIV co-infected and 35 (11.2\%) were hepatitis C/chronic kidney disease comorbid. There were 151 (98.1\%) of hepatitis C mono-infected, $110(88.7 \%)$ of hepatitis C/HIV and $20(57.1 \%)$ of hepatitis $\mathrm{C} /$ chronic kidney disease patients treated with 1 st line regimens. Significantly more patients who had co-morbidity with either HIV or chronic kidney disease were prescribed 2nd line regimens ( $8.1 \%$ and $37.1 \%$ respectively), compared to patients with hepatitis $\mathrm{C}$ mono-infection $(1.9 \%)(P$ value $<0.05)$. Comorbid patients $(12.1 \%$ of HIV and $25.8 \%$ of chronic kidney disease) were more likely to required drug-drug interactions advice (grade 5) than hepatitis $\mathrm{C}$ mono-infected (1.8\%). Higher cure rates were observed in hepatitis C mono-infected (95.33\%), hepatitis C/HIV (96.1\%) compared to hepatitis C/chronic kidney disease patients (90.3\%). Conclusion This study shows that treatment pathways permitting access to individual treatment adjustments in accordance with comorbidities and with consideration of drug-drug interaction in a multi-disciplinary team, provides successful outcomes in hepatitis C patients co-morbid with HIV or chronic kidney disease.
\end{abstract}

Keywords Chronic kidney disease $\cdot$ Clinical outcomes $\cdot$ Drug-drug interactions $\cdot$ Hepatitis C $\cdot$ HIV $\cdot$ Human immunodeficiency virus

Electronic supplementary material The online version of this article (https://doi.org/10.1007/s11096-020-00994-6) contains supplementary material, which is available to authorized users.

Vibhu Paudyal

v.paudyal@bham.ac.uk

1 Department of Pharmacy, Quaid-i-Azam University, Islamabad, Pakistan

2 Abertawe Bro Morgannwg University Health Board, Princess of Wales Hospital, Swansea, UK

3 Liver and Hepatobiliary Unit, University Hospitals Birmingham, Birmingham, UK

4 Department of Gastroenterology, Pakistan Institute of Medical Sciences, Islamabad, Pakistan

5 School of Pharmacy, University of Birmingham, Birmingham B15 2TT, UK

\section{Impacts on practice}

- With treatment adjustments in accordance with comorbidities and with consideration of drug-drug interaction, it is possible to achieve high cure rates for hepatitis $\mathrm{C}$ patients who have HIV or chronic kidney disease.

- Input from multi-disciplinary team in decision making for co-morbid hepatitis $\mathrm{C}$ infection is imperative in achieving desirable treatment outcomes. 


\section{Introduction}

Comorbidities substantially impact on the progression and treatment of hepatitis C [1]. Globally, an estimated 71 million people have chronic hepatitis $\mathrm{C}$ (CHC) [2]. In the United Kingdom (UK), about 160,000 people have CHC with injecting drug use (IDU) as the primary ( 90\%) mode of transmission [3]. The UK's Government hepatitis $\mathrm{C}$ action plan for England, identifies the need to scale-up treatment with new antiviral drugs if the burden of $\mathrm{CHC}$ is to be managed. Treating hepatitis $\mathrm{C}$ patients along with the comorbidities presents a considerable challenge for the health care providers $[4,5]$.

Certain comorbidities in CHC-infected patients may affect treatment outcomes, impair health related quality of life (HRQOL) [6, 7], and increase mortality associated with liver complications $[8,9]$. There are two co-morbidities particularly important in clinical practice when treating hepatitis C, namely, chronic kidney disease (CKD) and human immunodeficiency virus (HIV) infection. CKD patients are vulnerable to contracting hepatitis $\mathrm{C}$ during dialysis [10], if the procedure is carried out using poor sterilization practices. In the context of the UK, the number of patients with co-morbidity of HCV and CKD is significant and includes mainly patients who undergo frequent travel to South Asia or Africa and who receive dialysis treatment whilst on holidays [11-14].

Likewise, the co-morbidity of HIV is prevalent, particularly in Injecting drug users (IDUs) [15]. Liver associated disease such as hepatitis $\mathrm{C}$ is a major reason of morbidity and mortality in HIV-coinfection [16]. Also, HCV infection is being reported with increase in number among men who have sex with men (MSM) across Europe and the USA [17]. A Swiss cohort study has concluded that HCV infection accelerates the progression of HIV disease [18]. In $\mathrm{HCV}$ mono-infected patient, the progression of disease to cirrhosis takes almost 30 years in comparison to 15 years in co-infected patients [19].

The introduction of direct acting antivirals (DAAs) in 2011, and the further development of pan-genotypic DAAs, has provided highly effective and tolerable HCV drug regimens with cure rates greater than 95\% [20]. However, in clinical practice, special considerations are required when prescribing DAAs for HCV/HIV co-infected patients due to concomitant medications and a potential increased risk of drug-drug interactions [21, 22]. Similarly, in HCV/CKD comorbidity, owing to accelerated development of hepatic complications and complex drug regimens, personalized patient care is critical $[18,23,24]$. It is thought that a multidisciplinary team (MDT) approach inclusive of a prospective assessment of potential drug-drug interactions (DDIs) (prior to commencing $\mathrm{HCV}$ therapy), improves clinical outcomes and cure rates $[25,26]$.

In the UK, during 2016, twenty two Hepatitis C Operational Delivery Networks (ODNs) were launched to simplify patient access pathways to HCV testing and treatment services. The model encompasses a 'hub and spoke' approach with access to treatment being regulated by the hub that supports a specialised multi-disciplinary team to facilitate services at both the hub and at the spoke sites. This specialist team receives referrals of complicated, comorbid cases and ensures prospective evaluations and decision making for individualised patient care [27].

Alongside the implementation of the hepatitis C ODN within the UK, The National Health Service England (NHSE) introduced a hepatitis $\mathrm{C}$ treatment run rate card that sets clear prescribing guidelines for the hepatitis $\mathrm{C}$ regimens based on regimen prices. The guidelines stated that $90 \%$ of patients had to receive first line treatment, and that the use of second or third line treatment required review and approval from NHSE. As a result of the implementation of these guidelines, the MDT team were encouraged to make changes to the patients existing co-prescribed medication in order to avoid DDIs and comply with the run rate card, in preference to prescribing second or third line regimens.

\section{Aim of the study}

This study aimed to explore the treatment choices; taking into account the prospective identification of DDIs by specialist pharmacist and to compare clinical outcomes, in HCV mono-infected patients, and HCV patients with HIV or CKD comorbidities.

\section{Ethics approval}

The University Hospitals Birmingham (UHB) research and development committee reviewed this study and classified this as a service evaluation, hence not requiring full ethical submission. Necessary approval was then sought from the HR and the Clinical Audit Registration and Management System (CARMS-14077).

\section{Method}

An observational study was undertaken. Datasets of all HCV monoinfected patients and with HIV/CKD comorbidities that were referred to a large tertiary Liver Unit in the West Midlands, UK, between July 2015 and January 2018 were analyzed. 
Patients aged $\geq 18$ years with diagnosis of hepatitis C alone or co-infected with HIV or comorbid with CKD were eligible for this study. Pregnant females, children and HCV patient having comorbidities other than HIV or CKD were excluded. The relevant patients were identified through the database of hospital portal.

\section{Data collection and analysis}

A data collection tool was designed and moderated amongst the team of researchers including a senior medical consultant, a specialist pharmacist and a statistician. The data extraction was carried out by the study researcher and validated by the specialist pharmacist. Demography, ethnicity, mode of acquiring infection (sexual contact, IDU/people who inject drugs (PWID), perinatal exposure, iatrogenic exposure and other [tattoos, needle piercing, unknown]), genotype, baseline HCV viral load, HIV viral load, CD4 count, liver health status and data of monoinfected patients were collected from the tertiary liver unit databases and from the Clinical Portal (electronic interface containing patient records). Information detailing treatment history, medication prescribed was extracted from Clinical Portal/Prescribing, Information and Communication System (PICS) and referral forms (Appendix 1). The HCV regimen choice, along with any advice provided by the specialist pharmacist relating to the treatment choice, monitoring requirements and any requirements to change the patients existing medications were extracted from the correspondence found on clinical portal, minutes of the multi-disciplinary team meeting and PICS. Any missing information was pursued via request to the referring centre and follow up records were reviewed up to 12 weeks post end of treatment date.

Non-invasive transient elastography (using Echosens touch $502 \mathrm{C}$ scanner) was used to generate a fibroscan score which was used to determine the non-cirrhotic/cirrhotic status of each patient. A fibroscan score of $11.5 \mathrm{kPa}$ or above was regarded as cirrhotic liver for the purpose of the study.

Follow up and treatment outcomes were assessed based on HCV viral load measured at beginning of treatment, at end of treatment (ETR) and 12 weeks post end of treatment [12 weeks Sustained Virological Response (SVR)]. A viral load of $<12 \mathrm{IU} / \mathrm{ml} 12$ weeks post end of treatment was considered as undetectable level and was regarded as a cure. The final cure rate was reported in terms of modified intention to treat \% (mITT \%; considering the successfully treated patients and excluding patients who did not commence the treatment, stopped treatment early, those who were lost to follow up or were awaiting SVR12). The assessment of DDIs was carried out by the specialist pharmacist using the hepatitis C drug-drug interaction checker; Liverpool University, the electronic medicine compendium (eMC) for each drug and their clinical expertise. A coding tool was used to code DDIs. This tool was checked for face and content validity by the British Hepatitis Pharmacist Group (BHPG) which includes consultant pharmacist and specialist pharmacists working within the field of Hepatitis (Appendix 2). The codes explain risk rating and action required for potential drug-drug interactions.

All the data sets (anonymised) were sought from IT department at the tertiary centre and stored on password protected computers at all times. Statistical analyses were performed using SPSSV.24 (SAS Institute, Cary, NC). Frequency distribution and descriptive statistics were applied to demographic and baseline parameters. The Pearson Chi square test was applied to assess any difference of demographic, baseline and end point variables among groups and $P$ value of 0.05 or less were taken as statistically significant.

\section{Results}

A total of 313 patients met the inclusion criteria, of those 154 (49.2\%) were HCV monoinfected, 124 (39.6\%) HCV/ HIV co-infected and 35 (11.2\%) were HCV/CKD comorbid. The mean (SD) age was 51.9 (11.1) years. Two hundred and thirty four $(74.8 \%)$ were male and $180(57.5 \%)$ were white. Genotype 1a was the most prevalent 113 (36.1\%) followed by genotype $3 / 3 a-110(35.1 \%)$. A total of $102(32.6 \%)$ patients were PWIDs. Overall, one hundred and ninety two (61.3\%) were non-cirrhotic while cirrhosis was diagnosed in $121(38.7 \%)$ patients (Tables 1, 2).

In treatment choices, sofosbuvir (Sof)/ledipasvir $($ Led $) \pm$ ribavirin $(\mathrm{R})$ was the most $(\mathrm{n}=37)$ prescribed combination of DAAs for non-cirrhotic/treatment naive patients ombitasvir (Omb)/paritapravir (Par)/ritonavir (Rit)/dasabuvir (Das) $\pm \mathrm{R}$ was the second most prescribed combination $(n=23)$ and elbasvir (Elb)/grisepravir (Grz) $\pm R$ being the third most prescribed combination $(n=19)$ for this group of patients. Seventeen of the non-cirrhotic/treatment experienced patients received $\mathrm{Omb} / \mathrm{Par} / \mathrm{Rit} / \mathrm{Das} \pm \mathrm{R}$. There were 17 of cirrhotic/treatment naïve patients who were prescribed Sof/daclatasvir (Dac) $\pm R$, while in cirrhotic/treatment experienced patients, Sof/Led $\pm \mathrm{R}$ was prescribed to 20 patients. Figure 1 shows the range of treatment combinations prescribed.

The treatment choices were markedly influenced by genotype of $\mathrm{HCV}$ and appropriate selection of treatment regimen by MDT sustained individualized care. Resultantly, the patients with G1a were prescribed Sof/Led/+, - R 
Table 1 Demographic characteristics of patients; HCV, co-infected HCV/HIV and HCV/CKD $(n=313)$

\begin{tabular}{|c|c|c|c|c|}
\hline Demographic characteristics & $\begin{array}{l}\text { Total }(\mathrm{n}=313) \\
\mathrm{n}(\%)\end{array}$ & $\begin{array}{l}\mathrm{HCV}(\mathrm{n}=154) \\
\mathrm{n}(\%)\end{array}$ & $\begin{array}{l}\mathrm{HCV} / \mathrm{HIV}(\mathrm{n}=124) \\
\mathrm{n}(\%)\end{array}$ & $\begin{array}{l}\mathrm{HCV} / \mathrm{CKD}(\mathrm{n}=35) \\
\mathrm{n}(\%)\end{array}$ \\
\hline \multicolumn{5}{|l|}{ Gender } \\
\hline Female & $79(25.2)$ & $50(32.5)$ & $16(12.9)$ & $13(37.1)$ \\
\hline Male & $234(74.8)$ & $104(67.5)$ & $108(87.1)$ & $22(62.9)$ \\
\hline \multicolumn{5}{|l|}{ Age (years) } \\
\hline Mean (SD) & $51.9(11.1)$ & $50.3(12.4)$ & $46.10(10.4)$ & $59.23(10.6)$ \\
\hline \multicolumn{5}{|l|}{ Ethnicity/race } \\
\hline Asian or Asian British & $47(15.0)$ & $32(20.8)$ & $3(2.4)$ & $12(34.3)$ \\
\hline White & $180(57.5)$ & $56(36.4)$ & $104(83.9)$ & $20(55.6)$ \\
\hline Black, African, Caribbean or black British & $21(6.7)$ & $7(4.5)$ & $11(8.9)$ & $3(8.6)$ \\
\hline Mixed or multiple ethnic group & $2(0.6)$ & $1(0.6)$ & $1(0.8)$ & - \\
\hline Other ethnic group & $5(1.6)$ & $5(3.2)$ & - & \\
\hline Prefer not to say & $58(18.5)$ & $53(34.4)$ & $5(4.0)$ & - \\
\hline \multicolumn{5}{|l|}{ Mode of infection } \\
\hline Heterosexual/MSM & $10(3.2)$ & - & $8(6.5)$ & $2(5.7)$ \\
\hline IDU/PWID & $102(32.6)$ & $13(8.4)$ & $80(64.5)$ & $9(25.7)$ \\
\hline Iatrogenic/non-occupational & $31(9.9)$ & $8(5.2)$ & $4(3.2)$ & $19(54.3)$ \\
\hline Not known & $170(54.3)$ & $133(86.4)$ & $32(25.8)$ & $5(14.3)$ \\
\hline \multicolumn{5}{|l|}{ Genotype } \\
\hline $1 / 1 \mathrm{a}$ & $113(36.1)$ & $39(25.3)$ & $63(50.8)$ & $11(31.4)$ \\
\hline $1 b$ & $50(16.0)$ & $29(18.8)$ & $13(10.5)$ & $8(22.9)$ \\
\hline 2 & $5(1.6)$ & $3(1.9)$ & $2(1.6)$ & - \\
\hline $3 / 3 a$ & $110(35.1)$ & $70(45.5)$ & $26(21.0)$ & $14(40.0)$ \\
\hline $4 / 4 d$ & $33(10.5)$ & $12(7.8)$ & $19(15.3)$ & $2(5.7)$ \\
\hline $5 \mathrm{a}$ & $2(0.6)$ & $1(0.6)$ & $1(0.8)$ & - \\
\hline \multicolumn{5}{|l|}{ Baseline viral load ${ }^{\mathrm{a}}$} \\
\hline Very low viremic & $14(4.5)$ & $6(3.9)$ & $8(6.5)$ & - \\
\hline Low viremic & $37(11.8)$ & $11(7.1)$ & $22(17.7)$ & $4(11.4)$ \\
\hline Moderate viremic & $140(44.7)$ & $83(53.9)$ & $42(33.9)$ & $15(42.9)$ \\
\hline High viremic & $122(39.0)$ & $54(35.1)$ & $52(41.9)$ & $16(45.7)$ \\
\hline \multicolumn{5}{|l|}{ Liver disease status } \\
\hline Non cirrhotic & $192(61.3)$ & $68(44.2)$ & $102(82.3)$ & $22(62.9)$ \\
\hline Cirrhotic & $121(38.7)$ & $86(55.8)$ & $22(17.7)$ & $13(37.1)$ \\
\hline
\end{tabular}

$H I V$ human immunodeficiency virus, $C K D$ chronic kidney disease, $S D$ standard deviation, $I D U$ injecting drug user, $P W I D$ patient who inject drugs, $M S M$ men who have sex with men

${ }^{a}$ Viral load is represented as; very low viremic $=$ less than $8000 \mathrm{IU} / \mathrm{ml}$, low viremic $=8001-20,000 \mathrm{IU} / \mathrm{ml}$, moderate viremic $=20,001-$ $800,000 \mathrm{IU} / \mathrm{ml}$, and high viremic $=$ greater than $800,000 \mathrm{IU} / \mathrm{ml}$

$(\mathrm{n}=55), \mathrm{Omb} / \mathrm{Par} / \mathrm{Rit} / \mathrm{Das} /+,-\mathrm{R}(\mathrm{n}=30)$ and Elb/Grz/+, $-\mathrm{R}(\mathrm{n}=21)$. Similarly, patients having G3 infection were prescribed Sof/Dac/R $(n=42)$ Glecaprevir $($ Gle $) / \mathrm{Pib}(\mathrm{n}=18)$ and Sof/Velpatasvir $(\mathrm{Vel}) /+,-\mathrm{R}(\mathrm{n}=15)$.

\section{Clinical outcomes}

A total 151 (98.1\%) of HCV monoinfected, $110(88.7 \%)$ of $\mathrm{HCV} / \mathrm{HIV}$ and $20(57.1 \%)$ of $\mathrm{HCV} / \mathrm{CKD}$ patients were treated with 1 st line HCV treatment in line with NHSE recommendations. Significantly more patients who had co-morbidity with either HIV or CKD were prescribed 2nd line regimens $(n=10,8.1 \%$ and $n=13,37.1 \%$ respectively), compared to patients with HCV monoinfection $(n=3,1.9 \%)$ $(P$ value $<0.05)$. Two $(1.6 \%)$ of $\mathrm{HCV} / \mathrm{HIV}$ patients were treated with 3 rd line regimens. Two cases were deferred in each of $\mathrm{HCV} / \mathrm{HIV}$ and $\mathrm{HCV} / \mathrm{CKD}$ groups as change in concomitant medication was required (Table 2 ). 
Table 2 Patient's characteristics, treatment choices and outcomes $(\mathrm{n}=313)$

\begin{tabular}{|c|c|c|c|c|}
\hline Characteristics $(\mathrm{N}=313)$ & $\begin{array}{l}\mathrm{HCV}(\mathrm{n}=154) \\
\mathrm{n}(\%)\end{array}$ & $\begin{array}{l}\mathrm{HCV} / \mathrm{HIV}(\mathrm{n}=124) \\
\mathrm{n}(\%)\end{array}$ & $\begin{array}{l}\mathrm{HCV} / \mathrm{CKD}(\mathrm{n}=35) \\
\mathrm{n}(\%)\end{array}$ & $P$ value \\
\hline \multicolumn{5}{|l|}{ Genotype } \\
\hline $1 \mathrm{a}$ & $39(25.3)$ & $63(50.8)$ & $11(31.4)$ & $<0.001 *$ \\
\hline $1 b$ & $29(18.8)$ & $13(10.5)$ & $08(22.9)$ & \\
\hline 2 & $03(1.9)$ & $02(1.6)$ & - & \\
\hline $3 / 3 a$ & $70(45.5)$ & $26(21.0)$ & $14(40.0)$ & \\
\hline $4 / 4 d$ & $12(7.8)$ & $19(15.3)$ & $02(5.7)$ & \\
\hline 5 & $01(0.6)$ & $01(0.8)$ & - & \\
\hline \multicolumn{5}{|l|}{ Tx experience and liver status } \\
\hline Non-cirrhotic/naïve & $45(29.2)$ & $73(58.9)$ & $17(48.6)$ & $<0.001 *$ \\
\hline Non-cirrhotic/pre-treated & $23(14.9)$ & $29(23.4)$ & $05(14.3)$ & \\
\hline Cirrhotic/naïve & $39(25.3)$ & $14(11.3)$ & $10(28.6)$ & \\
\hline Cirrhotic/pre-treated & $47(30.5)$ & $08(6.5)$ & $03(8.6)$ & \\
\hline \multicolumn{5}{|l|}{ Tx choices } \\
\hline 1st line & $151(98.1)$ & $110(88.7)$ & $20(57.1)$ & $<0.001 *$ \\
\hline 2nd line & 03 (1.9) & $10(8.1)$ & $13(37.1)$ & \\
\hline 3rd line & - & $02(1.6)$ & - & \\
\hline Deferred/med change req. & - & $02(1.6)$ & $02(5.7)$ & \\
\hline \multicolumn{5}{|l|}{ Tx outcomes } \\
\hline Not commenced treatment & $01(0.6)$ & $12(9.7)$ & $02(5.7)$ & \\
\hline Stopped early, lost to FU & $02(1.3), 01(0.6)$ & 02 (1.6), 07 (5.6) & $02(5.7), 00$ & \\
\hline Completed treatment & $150(97.4)$ & $103(83.1)$ & $31(88.6)$ & \\
\hline SVR 12 achieved & $129(83.8)$ & $84(67.7)$ & $26(74.3)$ & $<0.001^{*}$ \\
\hline ETR achieved/awaiting SVR12 & $14(9.1)$ & $15(12.1)$ & $02(5.7)$ & \\
\hline SVR 12 not achieved (failed/relapsed) & $07(4.5)$ & $04(3.2)$ & $03(8.6)$ & \\
\hline mITT $\%$ cure rate & $95.3 \%$ & $96.1 \%$ & $90.3 \%$ & \\
\hline
\end{tabular}

$H C V$ hepatitis $\mathrm{C}$ virus, $H I V$ human immunodeficiency virus, $C K D$ chronic kidney disease, $T x$ treatment (1st line, 2nd line, 3rd line are in accordance with NHSE hepatitis C treatment run rate card at the time of treatment), SVR sustained virological response, $F U$ follow up, modified ITT modified intention to treat analysis; representing; Tx of HCV patients was approved at MDT but not commenced and ongoing treatments awaiting 12 week SVR

*Pearson Chi square test shows a significant difference ( $P$ value 0.05 or less) of the variable among treated groups

Fig. 1 Frequency of treatment choices considering liver injury and treatment experiences.

Elb elbasvir/grisepravir, Sof/

Led sofosbuvir/ledipasvir, Gle/

$P i b$ glecaprevir/pibrentasvir,

Omb/Par/Rit/Das ombitasvir/ paritapravir/ritonavir/dasabuvir, $R$ ribavirin, $P e g$ pegylated interferon, Sim simprevir, Led ledipasvir, Vel velpatasvir

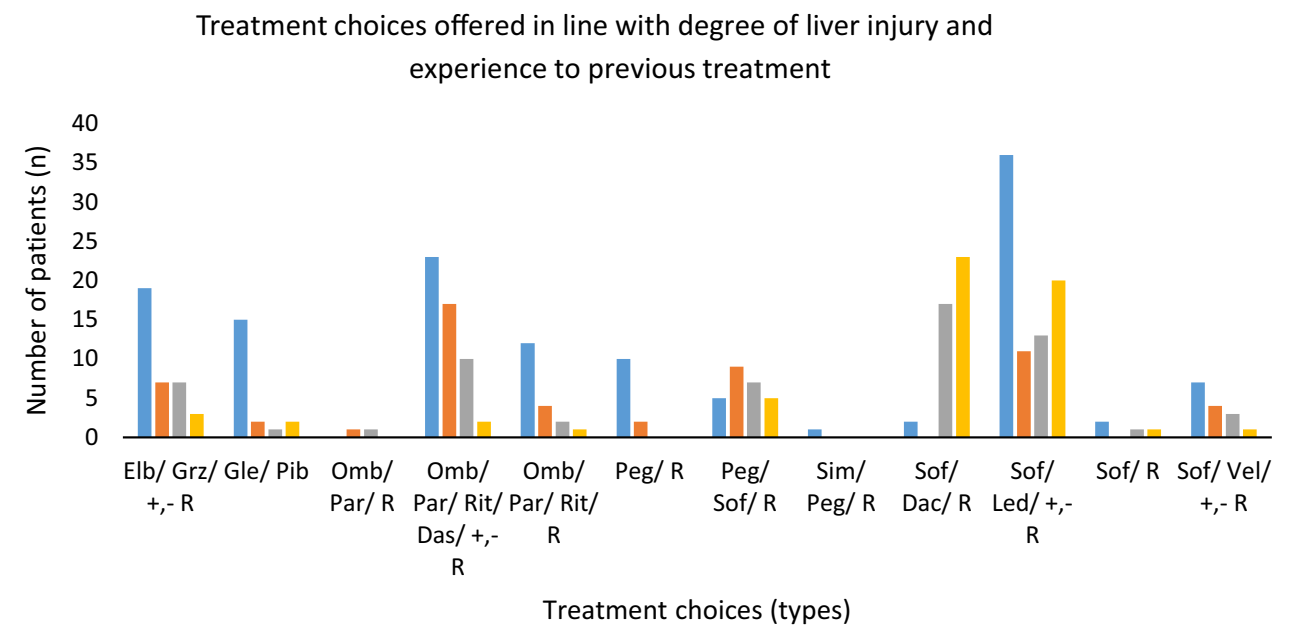

Non-cirrhotic/ Naive $\quad$ Non-cirrhotic/ Pre-treated $\quad$ Cirrhotic/ Naive $\quad$ Cirrhotic/ Pre-treated 
Fig. 2 Flow diagram showing the treatment outcomes of the study cohort. $M D T$ multidisciplinary team, $S V R$ sustained virologic response

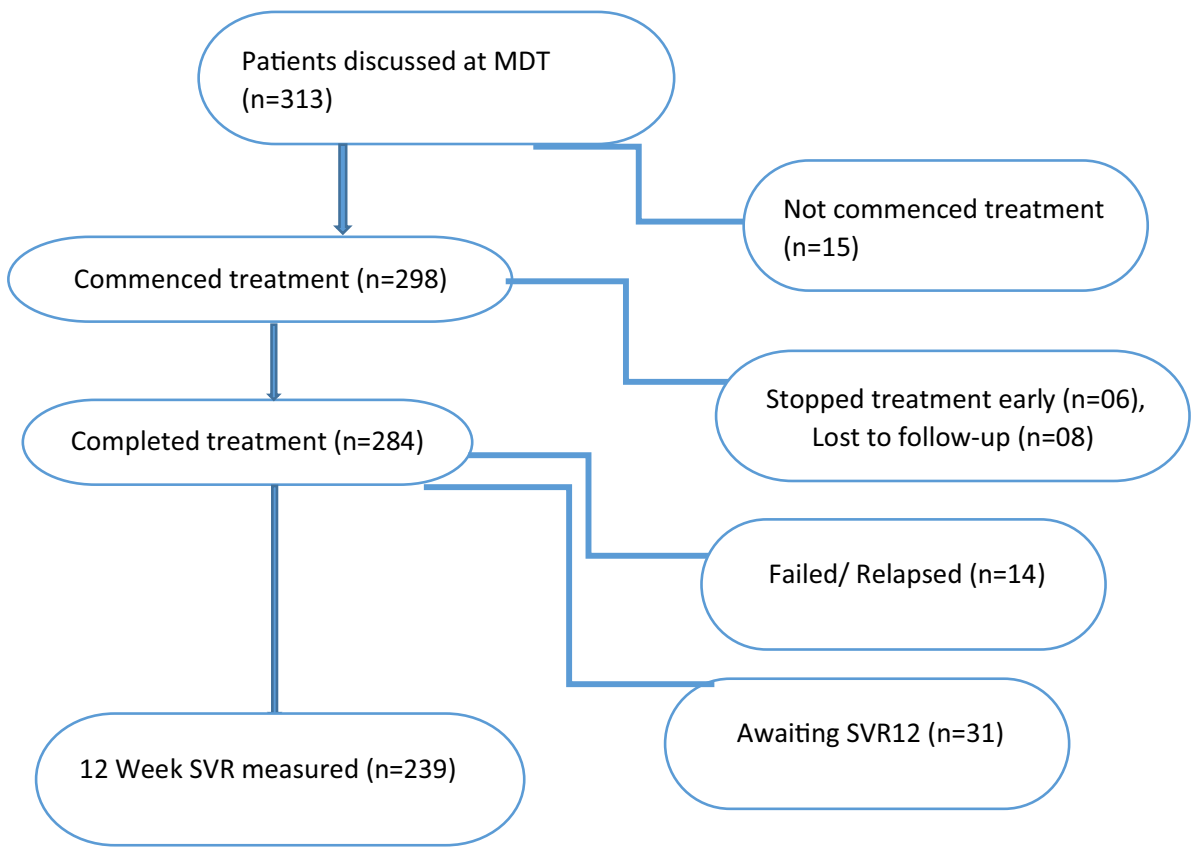

Of the total 313 patients, 239 (76.4\%) achieved 12 week SVR and 31 (9.9\%) achieved ETR and were awaiting 12 week post-treatment evaluation at the end of the study. Fourteen (4.5\%) failed/relapsed, $6(1.9 \%)$ discontinued treatment early, 8 (2.6\%) were lost to follow-up and 15 (4.8\%) did not progress to commence treatment beyond MDT decision. The overall mITT \% cure rate was $95.1 \%$ (Fig. 2 and Table 2).

When compared HCV/CKD co-morbid $(\mathrm{n}=28,90.3 \%)$ patients, a greater percentage of patients with $\mathrm{HCV}$ who were monoinfected or co-infected with HIV, achieved mITT \% (95.3\% of HCV monoinfected and $96.1 \%$ of HCV/ HIV respectively). The treatment choices, treatment outcomes and $\mathrm{mITT} \%$ analyses are detailed in Table 2 . There was no significant difference in treatment response in different ethnic groups; baseline viral load and SVR12 were similar in all ethnic groups (Table 2).

Overall, the concomitant medications with potential DDIs were cardiovascular medicines 83 (26.4\%), psychotropic medications 71 (22.7\%), acid suppressants 51 (16.2\%)
Fig. 3 Frequency of concomitant medication prescribed along with hepatitis $\mathrm{C}$ medicines. PPIs proton pump inhibitors, NSAIDs non-steroidal anti-inflammatory drugs, $C V S$ cardiovascular system drugs

\section{Frequency of concomitant medications}

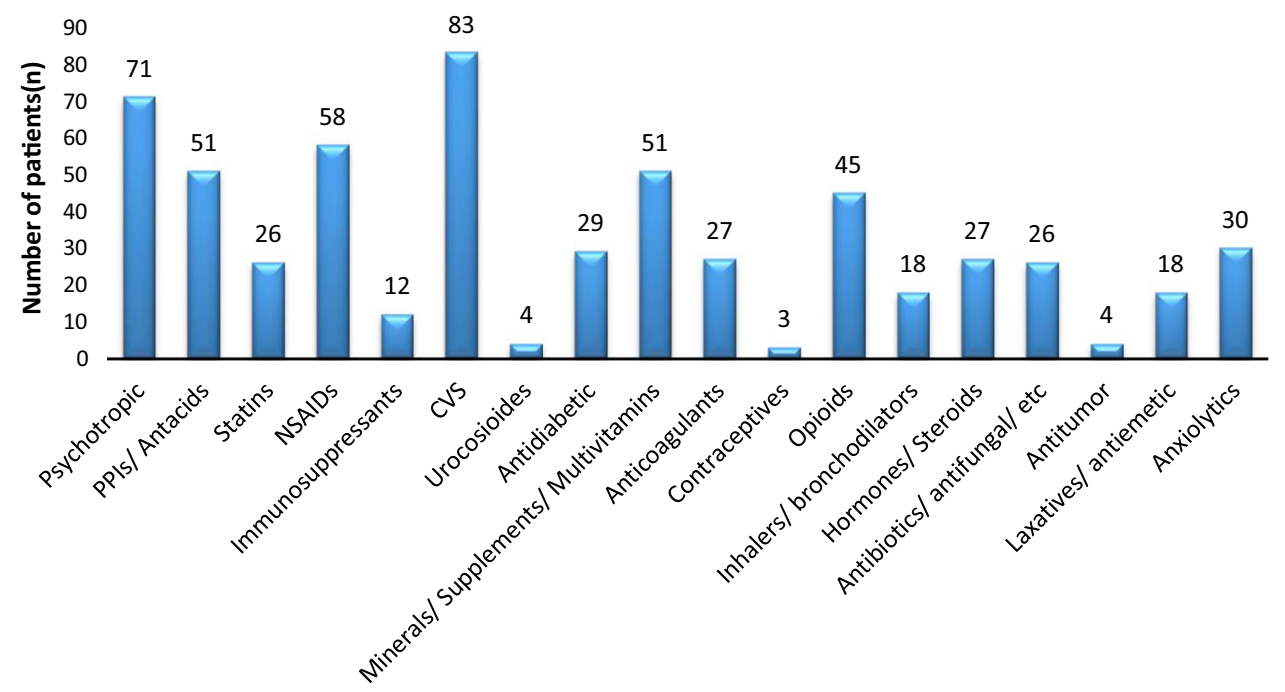

Types of concomitant medicines 
[Including lansoprazole, omeprazole, ranitidine], statins 26 $(8.3 \%)$ [Including atorvastatin, rosuvastatin, simvastatin, pravastatin, fluvastatin] and immunosuppressants (3.8\%) (Fig. 3).

The median (IQR) number of concomitant medicines per patient were 2 (1-4) in HCV monoinfected, 3 (2-5) in HCV/HIV (excluding the HIV medications) and 8 (4-9) in HCV/CKD patients. The potential DDIs with concomitant medications were identified in a total 21 (13.6\%) of $\mathrm{HCV}$ monoinfected patients, $56(45.2 \%)$ of HCV/HIV medication and 19 (54.3\%) of HCV/CKD medication (Table 3).

The MDT prospectively assessed the risk of potential DDIs and advised interventions/action of grade 3 for $11.6 \%$, $10.4 \%$ and $28.5 \%$ patients of $\mathrm{HCV}$-monoinfected, HCV/HIV and HCV/CKD groups respectively. Similarly, interventions of grade 5 were advised for $1.8 \%, 12.1 \%$ and $25.8 \%$ patients of HCV mono-infected, HCV/HIV and HCV/CKD groups respectively. While, interventions of grade 4 were advised for $22.7 \%$ of $\mathrm{HCV} / \mathrm{HIV}$ patients. There were more patients (76.2\%) in HCV mono-infected group that did not require any modification in treatment choices compared to $\mathrm{HCV} /$ HIV (24.2\%) and HCV/CKD patients (17.1\%) (Fig. 4 and Appendix 2).

\section{Discussion}

This study reports the selection and clinical effectiveness of the treatment choices in patients with HCV and concomitant comorbidities; specifically looking at the multidisciplinary management of DDIs in hepatitis $C$ treated patients in the UK. As per our results, treatment choices varied greatly due to the comorbidities. Treatment selection was made according to the individual patient's circumstances as observed in the shifting of 1 st line to 2 nd in treatment choices. This was required more frequently in the HIV and CKD comorbid patients. In addition, the genotype, previous treatment and the presence of liver cirrhosis influenced the treatment choice significantly. The non-cirrhotic/treatment naive patients required fewer interventions and modifications when compared to cirrhotic/ previously treated patients, who required greater interventions and treatment modifications.

This study confirms the importance of multi-disciplinary team (MDT) in decision making prospectively for HCV/HIV and HCV/CKD complicated cases [28]. This is demonstrated by results of mITT \% cure rate $95.3 \%, 96.1 \%$ and $90.3 \%$ of HCV monoinfected, HCV/HIV and HCV/CKD patients respectively. A number of patients from both the $\mathrm{HCV} / \mathrm{HIV}$ and the HCV/CKD groups however, either stopped the treatment early or were lost to follow-up. In HCV/HIV group, $2(1.6 \%)$ patients stopped the treatment early and $7(5.6 \%)$ were lost to follow-up, while in CKD, 2 (5.7\%) patients 


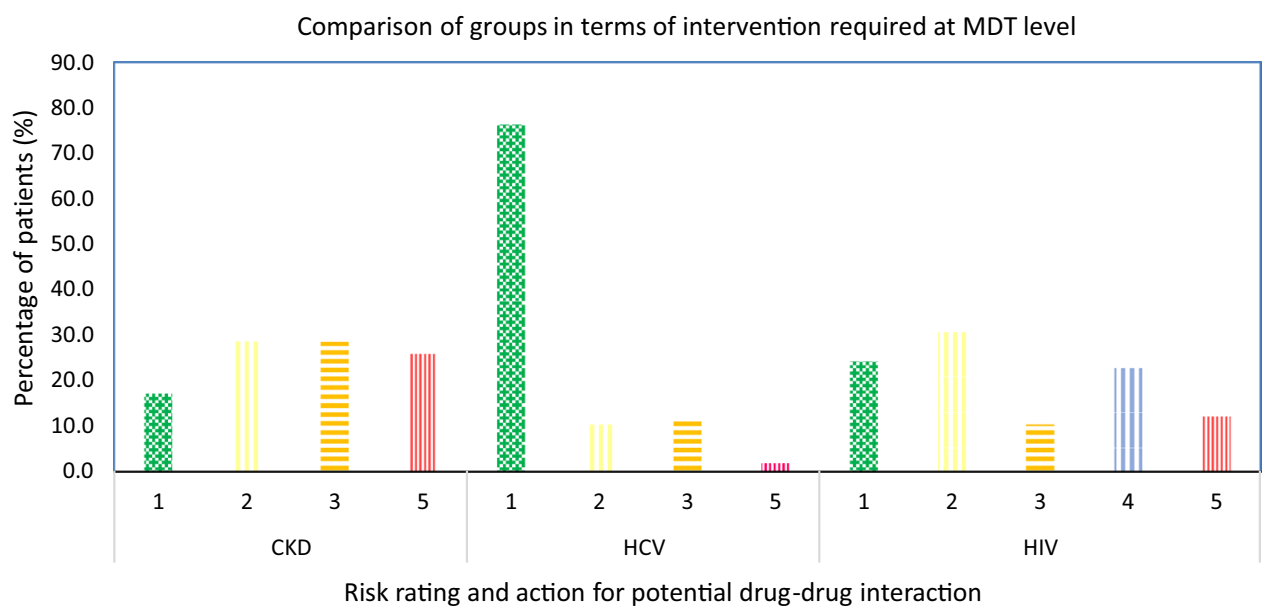

Fig. 4 Prospective assessment of DDIs and interventions advised by multidisciplinary team (MDT). $H C V$ hepatitis $\mathrm{C}$ virus, $C K D$ chronic kidney disease, $H I V$ human immunodeficiency virus. Risk rating and relevant interventions; $1=$ no known drug-drug interaction/no action

stopped treatment early due to intolerable side effects. There were $4(3.2 \%)$ treatment failures in HCV/HIV and $3(8.6 \%)$ treatment failure in $\mathrm{HCV} / \mathrm{CKD}$ comorbid patients. It's worth noting that patients lost to follow up by the hepatology team in the HCV/HIV group, may have simply continued follow up by the HIV treating team.

At present, in the study setting, the access to DAA treatment for complicated cases such as those with HIV or CKD is dependent upon the referral to a specialist centre. The referral permits the specialist team to prospectively assess the patient's clinical needs. This process includes an assessment of potential DDIs which contributes to the decisions surrounding the selection of the most appropriate HCV regimen. This model supports individualized patient's care, the success of which is reflected in the high cure rates achieved. The findings of our study is provides addition in evidence to the currently available literature $[29,30]$ about the impact of pharmacist intervention and involvement as part of the MDT to address the DDIs associated with HCV management. While the burden of DDIs and co-morbidities in HCV have been previously illustrated [29], patient outcomes in relation to MDT interventions had not been explored before. Findings conforms with literature in other clinical areas which have demonstrated that inclusion of pharmacist in MDT with needed, $2=$ advice on monitoring or counselling given by pharmacist, $3=$ concomitant drug regimen changed, $4=$ DDI with HIV/HCV regimen requiring a change in the HIV regimen or additional monitoring requirements and $5=\mathrm{HCV}$ drug regimen changed

specific roles such as customization of treatment choices, dose modifications to improve adherence and prevention and management can help attain desirable treatment outcomes [31, 32].

DAA treatment choices conferred a success rate (mITT\% cure) of $95.3 \%$ in HCV mono-infected and $96.1 \%, 90.3 \%$ for HIV and CKD comorbid patients respectively. Other comorbidities were common in the overall cohort and consequently the use of concomitant medication having potential DDIs was observed high with cardiovascular medicines 83 (26.4\%) and psychotropic medications 71 (22.7\%).

\section{Study strengths and limitations}

This study has explored the role of multi-disciplinary team (MDT) in management of $\mathrm{HCV}$ and comorbid patients. Data was collected from a large tertiary hospital with adequate sample size for the planned statistical analyses of comparative outcome measurements. Validated and recognised data sources were used for all information on treatment choices and clinical outcomes.

This study has limitations. Firstly, the investigators were unable to access the data for mono-infected patients from the referring centres as only complicated cases are referred 
to the tertiary centre. Therefore, the PICS data (available at tertiary Liver unit) were used for the mono-infected patients. Secondly, the HIV or CKD and related treatment or management was ultimately under the control of respective departments, and thus the hepatitis C MDT relied on the respective departments to act on recommendations accordingly. Finally, this study was specific to the population served by the tertiary centre and may not reflect the whole population within the UK or further afield. In addition to the limitations listed, it's worth noting at this stage that the study observation period was pre the introduction of Glecaprevir/pibrentasvir, thus patients with genotype 3 (G3) HCV and CKD were generally not referred to the MDT during the study period since the available treatment at that time contained a sofosbuvir back bone which is contraindicated in CKD. The population of CKD patient included in the study is small and predominantly included Genotype 1 (G1) and G3 HCV infections.

\section{Future research}

This study highlights the role of a multi-disciplinary healthcare professionals' input into the management of hepatitis $\mathrm{C}$ patients co-morbid with HIV or CKD. Based on our results, it is recommended that a future research work should include other co-morbid patients to explore the success of specialist hepatitis MDT regarding treatment outcomes in complex cases.

\section{Conclusion}

This study shows that treatment pathways permitting access to specialised MDT care benefits HCV population who have HIV or CKD comorbidities. Individual treatment adjustments (in accordance with comorbidities, genotype and previous treatment experience) and consideration of drug-drug interaction by specialist pharmacist is likely to provide successful outcomes in HCV patients co-morbid with HIV or CKD.

Appropriate selection of DAAs to target HCV infection which presents with comorbidities can be enhanced through the inclusion and advice of a specialist pharmacist in a MDT setting.

Acknowledgements We are grateful to the Hepatitis C Operational Delivery Network (ODN) team at University Hospitals Birmingham and the lead nursing staff from the spokes centers for their support during the conduct of the study. We appreciate the rapid response and permissions by the Human resource team at Queen Elizabeth Hospital Birmingham, United Kingdom. SA is thankful to the Higher Education Commission of Pakistan for the financial support permitting opportunity to visit and study at the University of Birmingham, Birmingham UK. We acknowledge the contribution of Dr. Sayeed Haque (UOB) during initial discussions on statistical analysis.

Funding SA is grateful to the Higher Education Commission of Pakistan (Grant No. IRSIP 37 PSc17) for financial support during study, travel and stay at University of Birmingham, Birmingham UK. No other funding was received for the conduct of this study.

Data availability Technical appendix, statistical sheets, and dataset will be available from the Dryad repository and corresponding author at v.paudyal@bham.ac.uk.

Conflicts of interest All authors have no conflicts of interests to declare.

Open Access This article is licensed under a Creative Commons Attribution 4.0 International License, which permits use, sharing, adaptation, distribution and reproduction in any medium or format, as long as you give appropriate credit to the original author(s) and the source, provide a link to the Creative Commons licence, and indicate if changes were made. The images or other third party material in this article are included in the article's Creative Commons licence, unless indicated otherwise in a credit line to the material. If material is not included in the article's Creative Commons licence and your intended use is not permitted by statutory regulation or exceeds the permitted use, you will need to obtain permission directly from the copyright holder. To view a copy of this licence, visit http://creativecommons.org/licenses/by/4.0/. 


\section{Appendix 1}

Viral Hepatitis MDT Referral Form.

University Hospitals Birmingham W/TS

\begin{tabular}{|l|l|}
\hline Name: & Gender: \\
\hline DOB: & NHS number: \\
\hline Already known to QEHB? Yes/No & QEHB Hospital number: \\
\hline Weight: & Referrer: \\
\hline
\end{tabular}

Bloods within 4 weeks - (Please attach flowsheet if available)

\begin{tabular}{|l|l|l|l|}
\hline AST: & ALT: & ALP: & Bilirubin: \\
\hline Albumin: & $\mathrm{Hb}:$ & Platelets: & INR: \\
\hline Cr / eGFR: & Ur: & Na: & K: \\
\hline
\end{tabular}

Hepatitis Information.

\begin{tabular}{|l|l}
\hline Genotype: & Subtype (for genotype 1): \\
\hline
\end{tabular}

Titre: (within 3 months)

Previous treatment episodes \& response:

(Please attach flowsheet if available)

Assessment of Fibrosis stage.

\begin{tabular}{|l|l|}
\hline Stage of disease: & Date of assessment: \\
\hline Fibro Scan: & Imaging: \\
\hline Biopsy: & \multicolumn{1}{|l}{} \\
\cline { 1 - 2 } &
\end{tabular}

Co-Morbidities:

(Significant co-morbidity - specifically alcohol, ongoing drug use, coinfection with HIV or HBV, other relevant comorbidity e.g. Psych history, IHD etc)

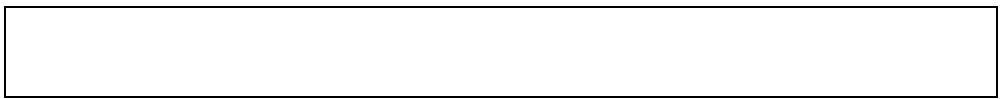

Medication:

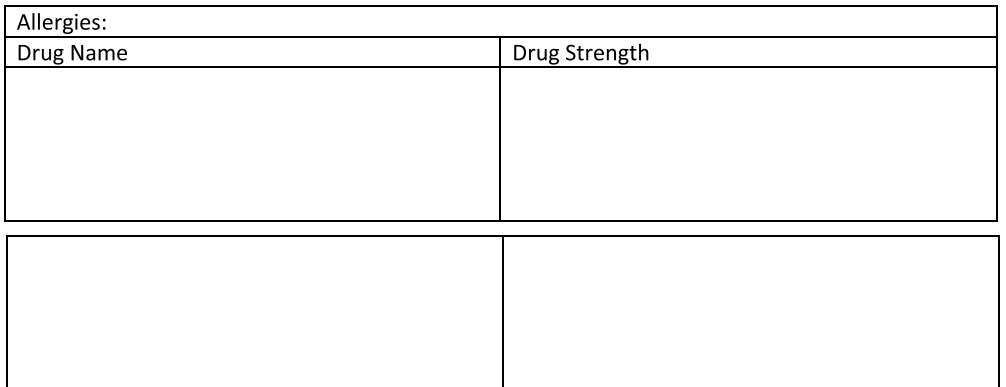

Exceptions to NHSE-preferred first line treatment

NHSE now require that patients should preferentially receive the treatment which is associated with the lowest acquisition cost. If the treatment with the lowest acquisition cost is not thought to be suitable/appropriate for a specific patient, then that patient must be referred to the Central MDT for discussion.

In this case, please document below the reasons for not using the treatment with lowest acquisition cost. 


\section{Appendix 2}

See Table 4.

Table 4 Rating of risks, action and description for potential drug-drug interaction risk rating and action for potential drug-drug interaction

\begin{tabular}{|c|c|c|}
\hline $\begin{array}{l}\text { Clas- } \\
\text { sification } \\
\text { (grade) }\end{array}$ & Action & Description \\
\hline 1 & No known drug-drug interaction/no action needed & Discussed at MDT and no potential DDI identified \\
\hline 2 & Advice on monitoring or counselling given by pharmacist & $\begin{array}{l}\text { Discussed at MDT. Advice given by pharmacist regarding additional } \\
\text { monitoring requirements/counselling points }\end{array}$ \\
\hline 3 & Concomitant drug regimen changed & $\begin{array}{l}\text { Discussed at MDT. Advice given regarding changing/omitting concomi- } \\
\text { tant medications (excluding HIV drug regimens) }\end{array}$ \\
\hline 4 & $\begin{array}{l}\text { DDI with HIV/HCV regimen requiring a change in the } \\
\text { HIV regimen or additional monitoring requirements }\end{array}$ & $\begin{array}{l}\text { Discussed at MDT. Advice given regarding changing HIV regimen prior } \\
\text { to commencing the hepatitis } \mathrm{C} \text { treatment or additional monitoring } \\
\text { requirements as a result of drug-drug interactions between the HIV/ } \\
\text { HCV regimens }\end{array}$ \\
\hline 5 & $\mathrm{HCV}$ drug regimen changed & $\begin{array}{l}\text { Discussed at MDT. Advice given regarding deviating from 1st line HCV } \\
\text { regimen (in accordance with the current NHSE Run rate card at the } \\
\text { time of treatment) due to drug-drug interactions }\end{array}$ \\
\hline
\end{tabular}

MDT multidisciplinary team, DDI drug-drug interactions, HIV human immunodeficiency virus, $H C V$ hepatitis C virus, NHSE National Health Services England

\section{References}

1. Louie KS, St Laurent S, Forssen UM, Mundy LM, Pimenta JM. The high comorbidity burden of the hepatitis $\mathrm{C}$ virus infected population in the United States. BMC Infect Dis. 2012;12(1):86.

2. World Health Organization. Progress report on access to hepatitis $\mathrm{C}$ treatment: focus on overcoming barriers in low-and middleincome countries. Geneva: World Health Organization; 2018.

3. Turner J, Bansi L, Gilson R, Gazzard B, Walsh J, Pillay D, et al. The prevalence of hepatitis $\mathrm{C}$ virus (HCV) infection in HIVpositive individuals in the $\mathrm{UK}$ - trends in $\mathrm{HCV}$ testing and the impact of HCV on HIV treatment outcomes. J Viral Hepat. 2010;17(8):569-77.

4. Harris RJ, Thomas B, Griffiths J, Costella A, Chapman R, Ramsay $\mathrm{M}$, et al. Increased uptake and new therapies are needed to avert rising hepatitis C-related end stage liver disease in England: modelling the predicted impact of treatment under different scenarios. J Hepatol. 2014;61(3):530-7.

5. World Health Organization. Guidelines for the screening, care and treatment of persons with chronic hepatitis C infection. Geneva: World Health Organization; 2016.

6. El-Zayadi AR. Hepatitis $\mathrm{C}$ comorbidities affecting the course and response to therapy. World J Gastroenterol. 2009;15(40):4993.

7. Hussain KB, Fontana RJ, Moyer CA, Su GL, Sneed-Pee N, Lok AS. Comorbid illness is an important determinant of healthrelated quality of life in patients with chronic hepatitis C. Am J Gastroenterol. 2001;96(9):2737.

8. Harris HE, Ramsay ME, Heptonstall J, Soldan K, Eldridge KP, HCV National Register Steering Group. The HCV National Register: towards informing the natural history of hepatitis $\mathrm{C}$ infection in the UK. J Viral Hepat. 2000;7(6):420-7.

9. Matta B, Lee TH, Patel K. Use of non-invasive testing to stage liver fibrosis in patients with HIV. Curr HIV/AIDS Rep. 2016;13(5):279-88.
10. Al-Wakeel J, Malik GH, Al-Mohaya S, Mitwalli A, Baroudi FE, El $\mathrm{Gamal} \mathrm{H}$, et al. Liver disease in dialysis patients with antibodies to hepatitis C virus. Nephrol Dial Transplant. 1996;11(11):2265-8.

11. Ericsson $\mathrm{CD}$. Travellers with pre-existing medical conditions. Int J Antimicrob Agents. 2003;21(2):181-8.

12. Tu AW, Buxton JA, Whitlock M, et al. Prevalence and incidence of hepatitis $\mathrm{C}$ virus in hemodialysis patients in British Columbia: follow-up after a possible breach in hemodialysis machines. Can J Infect Dis Med Microbiol. 2009;20(2):e19-23.

13. Johnson DF, Leder K, Torresi J. Hepatitis B and C infection in international travelers. J Travel Med. 2013;20(3):194-202.

14. Jadoul M, Poignet JL, Geddes C, Locatelli F, Medin C, Krajewska $\mathrm{M}$, et al. The changing epidemiology of hepatitis $\mathrm{C}$ virus (HCV) infection in haemodialysis: European multicentre study. Nephrol Dial Transplant. 2004;19(4):904-9.

15. Hagan H, Jarlais DC. HIV and HCV infection among injecting drug users. Mt Sinai J Med. 2000;67(5-6):423-8.

16. Milazzo L, Lai A, Calvi E, Ronzi P, Micheli V, Binda F, et al. Direct-acting antivirals in hepatitis $\mathrm{C}$ virus (HCV)-infected and HCV/HIV-coinfected patients: real-life safety and efficacy. HIV Med. 2017;18(4):284-91.

17. Ireland G, Delpech V, Kirwan P, Croxford S, Lattimore S, Sabin $\mathrm{C}$, et al. Prevalence of diagnosed HIV infection among persons with hepatitis C virus infection: England, 2008-2014. HIV Med. 2018;19(10):708-15.

18. Greub G, Ledergerber B, Battegay M, Grob P, Perrin L, Furrer $\mathrm{H}$, et al. Clinical progression, survival, and immune recovery during antiretroviral therapy in patients with HIV-1 and hepatitis C virus coinfection: the Swiss HIV Cohort Study. Lancet. 2000;356(9244):1800-5.

19. Bonacini M, Puoti M. Hepatitis $C$ in patients with human immunodeficiency virus infection: diagnosis, natural history, meta-analysis of sexual and vertical transmission, and therapeutic issues. Arch Intern Med. 2000;160(22):3365-73.

20. Pockros PJ, Reddy KR, Mantry PS, Cohen E, Bennett M, Sulkowski MS, et al. Efficacy of direct-acting antiviral combination for patients with hepatitis $\mathrm{C}$ virus genotype 1 infection and 
severe renal impairment or end-stage renal disease. Gastroenterology. 2016;150(7):1590-8.

21. Naggie S, Sulkowski MS. Management of patients coinfected with HCV and HIV: a close look at the role for direct-acting antivirals. Gastroenterology. 2012;142(6):1324-34.

22. Seden K, Back D. Directly acting antivirals for hepatitis C and antiretrovirals: potential for drug-drug interactions. Curr Opin HIV AIDS. 2011;6(6):514-26.

23. Molino CD, Carnevale RC, Rodrigues AT, Moriel P, Mazzola PG. HIV pharmaceutical care in primary healthcare: improvement in CD4 count and reduction in drug-related problems. Curr Opin HIV AIDS. 2017;25(5):724-33.

24. Azmi AN, Tan SS, Mohamed R. Hepatitis C and kidney disease: an overview and approach to management. World J Hepatol. 2015;7(1):78.

25. Taylor LE, Swan T, Mayer KH. HIV coinfection with hepatitis C virus: evolving epidemiology and treatment paradigms. Clin Infect Dis. 2012;55(1):S33-42.

26. Banerjee D, Reddy KR. safety and tolerability of direct-acting anti-viral agents in the new era of hepatitis $C$ therapy. Aliment Pharmacol Ther. 2016;43(6):674-96.

27. Parkes J, Roderick P, Bennett-Lloyd B, Rosenberg W. Variation in hepatitis $\mathrm{C}$ services may lead to inequity of health-care provision: a survey of the organisation and delivery of services in the United Kingdom. BMC Public Health. 2006;6(1):3.
28. Lee A, Hanson J, Fox P, Spice G, Russell D, Boyd P. A decentralised, multidisciplinary model of care facilitates treatment of hepatitis C in regional Australia. J Virus Erad. 2018;4(3):160.

29. Christensen S, Marra F, Kostev K. High rates of comorbidities and polypharmacy in patients with chronic hepatitis $\mathrm{C}$ in Germany: results of a large cross-sectional study. Z Gastroenterol. 2015;53(08):KG140.

30. Raine R, Wallace I, Nic a'Bháird C, Xanthopoulou P, Lanceley A, Clarke A, et al. Improving the effectiveness of multidisciplinary team meetings for patients with chronic diseases: a prospective observational study. Health Serv Deliv Res. 2014;2(37):1-72.

31. Lopez-Martin C, Siles MG, Alcaide-Garcia J, Felipe VF. Role of clinical pharmacists to prevent drug interactions in cancer outpatients: a single-centre experience. Int J Clin Pharm. 2014;36(6):1251-9.

32. Yang S, Britt RB, Hashem MG, Brown JN. Outcomes of pharmacy-led hepatitis $\mathrm{C}$ direct-acting antiviral utilization management at a veterans affairs medical center. J Manag Care Spec Pharm. 2017;23(3):364-9.

Publisher's Note Springer Nature remains neutral with regard to jurisdictional claims in published maps and institutional affiliations. 